
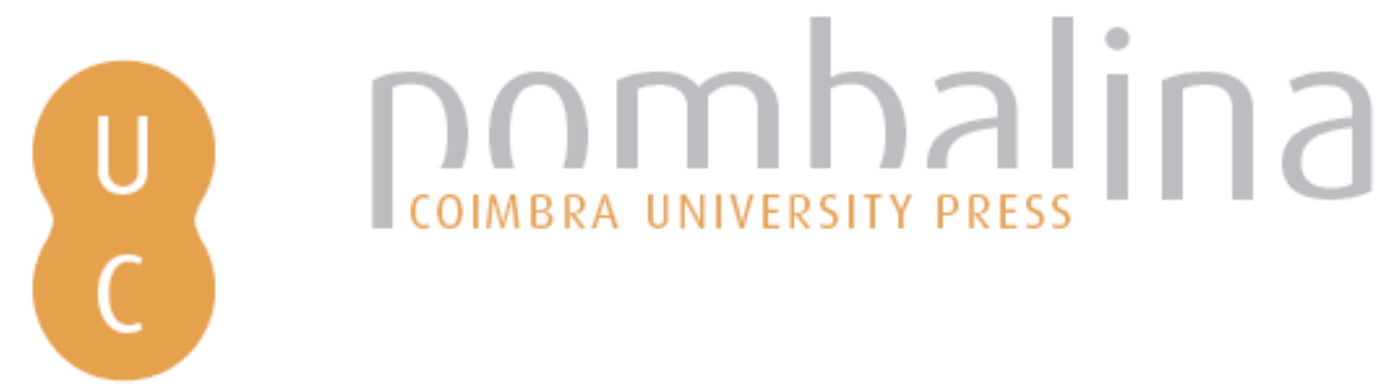

\title{
La impartición de las asignaturas de representación de la información en forma semipresencial en la Universidad de León: luces y sombras de una nueva experiencia
}

\author{
Autor(es): $\quad$ Rodríguez Bravo, Blanca
}

Publicado por: Imprensa da Universidade de Coimbra

URL persistente:

URI:http://hdl.handle.net/10316.2/31901

DOI:

DOI:http://dx.doi.org/10.14195/978-989-26-0319-3_22

Accessed : $\quad$ 26-Apr-2023 11:55:32

A navegação consulta e descarregamento dos títulos inseridos nas Bibliotecas Digitais UC Digitalis, UC Pombalina e UC Impactum, pressupõem a aceitação plena e sem reservas dos Termos e Condições de Uso destas Bibliotecas Digitais, disponíveis em https://digitalis.uc.pt/pt-pt/termos.

Conforme exposto nos referidos Termos e Condições de Uso, o descarregamento de títulos de acesso restrito requer uma licença válida de autorização devendo o utilizador aceder ao(s) documento(s) a partir de um endereço de IP da instituição detentora da supramencionada licença.

Ao utilizador é apenas permitido o descarregamento para uso pessoal, pelo que o emprego do(s) título(s) descarregado(s) para outro fim, designadamente comercial, carece de autorização do respetivo autor ou editor da obra.

Na medida em que todas as obras da UC Digitalis se encontram protegidas pelo Código do Direito de Autor e Direitos Conexos e demais legislação aplicável, toda a cópia, parcial ou total, deste documento, nos casos em que é legalmente admitida, deverá conter ou fazer-se acompanhar por este aviso.

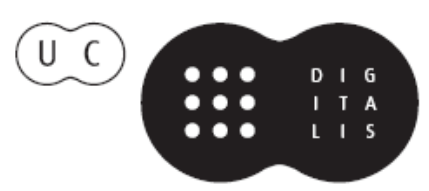


Maria Manuel Borges

Elias Sanz Casado

Coordenação

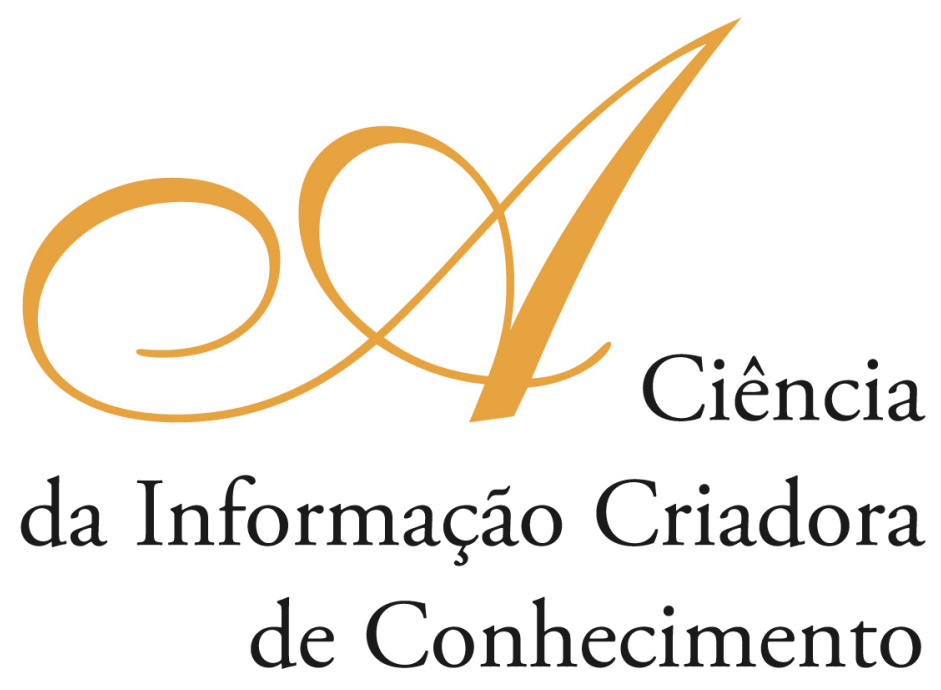

Vol. I

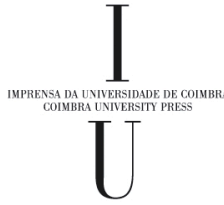

- COIMBRA 2009 


\author{
Blanca Rodríguez Bravo \\ Universidad de León (Espanha)
}

\title{
Resumen
}

El objetivo de este trabajo es el análisis de la satisfacción de los alumnos semipresenciales de la Diplomatura de Biblioteconomía y Documentación de la Universidad de León con la metodología utilizada para la transmisión de contenidos y dotación de competencias en las asignaturas de Análisis Documental (catalogación), Análisis del Contenido Documental y Lenguajes Documentales. Para conocer sus opiniones se ha entregado una encuesta a los estudiantes en junio de 2009. Asimismo, se ha estudiado el nivel de rendimiento y de éxito de dichos alumnos en relación con los datos globales de la Diplomatura.

\begin{abstract}
The aim of this paper is the analysis of the satisfaction of the distance learning students with the methodology used for teaching on line three subjects in the Diplomatura de Biblioteconomía y Documentación at the Universidad de León (LIS degree): Análisis Documental (cataloguing), Análisis del Contenido Documental (abstracting and indexing) and Lenguajes Documentales (indexing languages). The views of the blended learning students are gathered using a survey filled in 2009. Results on exams of these students in June 2009 are placed in relation to the overall values given for the whole of LIS degree.
\end{abstract}

\section{Introducción}

La Universidad de León inició en el curso 2006-2007 la impartición en modalidad semipresencial de la titulación de Biblioteconomía y Documentación. En junio de 2009 se ha graduado la primera promoción de alumnos que ha cursado la diplomatura en esta modalidad, de ahí que este encuentro nos pareciera idóneo para reflexionar sobre la experiencia.

Dado que en el nuevo Grado en Información y Documentación adaptado al Espacio Europeo, que las universidades están en proceso de implantación, disminuye el uso de la lección magistral y aumenta la necesidad de que los alumnos trabajen de forma semiautónoma, algunas experiencias docentes desarrolladas en la Universidad de León pueden resultar de interés para otros profesores que impartan docencia en asignaturas similares, nos referimos a asignaturas adscribibles al perfil de Representación de la información y/o Organización del conocimiento. 
En definitiva, como la Universidad de León se propone impartir el Grado en Información y Documentación de modo semipresencial exclusivamente, el conocimiento de los puntos fuertes y débiles de esta modalidad de enseñanza resulta imprescindible al igual que la voluntad de transformación de las debilidades en oportunidades para la mejora continua. Evaluar para evolucionar parece la fórmula idónea.

El análisis general sobre la nueva experiencia de la enseñanza semipresencial en la Universidad de León ya se llevó a cabo en 2008 y se expuso en el anterior encuentro de EDIBCIC (Rodríguez Bravo y Morán Suárez, 2008).

Para llevar a cabo este primer estudio se distribuyó una encuesta en enero de 2008 a los estudiantes que comenzaron sus estudios en el curso 2006-2007 y a los profesores que impartieron docencia en ese primer curso. Por lo que se refiere a los resultados obtenidos de la encuesta cumplimentada por los alumnos, en el estudio señalado se ponía de relieve que existía una gran satisfacción sobre los estudios realizados el $60 \%$ de los estudiantes se hallaba satisfechos y el $40 \%$ muy satisfecho con los resultados obtenidos. Este dato correlaciona con el éxito de los resultados alcanzados en los exámenes, la práctica totalidad de los encuestados lograron superar el curso. La valoración efectuada por el profesorado resultó también muy positiva. Todos los profesores manifestaron estar muy satisfechos $(62,5 \%)$ o satisfechos $(37,5 \%)$ con esta nueva propuesta de enseńanza-aprendizaje.

Los datos que presentamos en las tablas siguientes nos han sido facilitados por la Oficina de Calidad de la Universidad de León.

Por lo que se refiere a los datos generales de matricula para la titulación de Biblioteconomía y Documentación de los últimos años, es decir del curso 2006-2007 en adelante, curso en que comenzó la modalidad semipresencial, se ha constatado un incremento en la matrícula en la titulación, constituyéndose los alumnos semipresenciales en el núcleo principal de los estudiantes matriculados en los tres cursos de andadura de la nueva experiencia.

Tabla 1 - Alumnos matriculados

\begin{tabular}{|l|c|c|c|}
\hline Cursos & Matriculados & Nuevo ingreso & Primera opción \\
\hline $\mathbf{2 0 0 2 - 2 0 0 3}$ & 151 & 20 & $85 \%$ \\
\hline $\mathbf{2 0 0 3 - 2 0 0 4}$ & 118 & 21 & $96 \%$ \\
\hline $\mathbf{2 0 0 4 - 2 0 0 5}$ & 88 & 19 & $93 \%$ \\
\hline $\mathbf{2 0 0 5 - 2 0 0 6}$ & 74 & 13 & $100 \%$ \\
\hline $\mathbf{2 0 0 6 - 2 0 0 7}$ & 58 & 25 & $100 \%$ \\
\hline $\mathbf{2 0 0 7 - 2 0 0 8}$ & 65 & 30 & $100 \%$ \\
\hline $\mathbf{2 0 0 8 - 2 0 0 9}$ & 74 & 36 & $86 \%$ \\
\hline
\end{tabular}

Como se puede constatar el número de alumnos que optaron por la Diplomatura de Biblioteconomía y Documentación en primera opción es elevado, de ahí que se considere que se trata de estudiantes motivados, sobre todo en el caso de los alumnos semipresenciales que son estudiantes de mayor edad, algunos trabajando en el sector de la Información y Documentación.

En cuanto al grado de dedicación de los alumnos, es decir al número total de créditos matriculados por los estudiantes de la titulación se observa, como muestra la tabla siguiente, una dedicación moderada, ya que no se alcanzan los 60 créditos 
matriculados, y estable en el tiempo. Durante los últimos cursos no nos puede extrañar que el número de créditos que los estudiantes matriculan de media no sea elevado dado el numeroso grupo de alumnos en la opción semipresencial, que son estudiantes incorporados al mundo laboral mayoritariamente y que tienen la necesidad de distribuir el tiempo entre trabajo y estudios.

Tabla 2 - Dedicación lectiva por estudiante

\begin{tabular}{|l|c|}
\hline Cursos & Créditos matriculados \\
\hline $\mathbf{2 0 0 2 - 2 0 0 3}$ & 51 \\
\hline $\mathbf{2 0 0 3 - 2 0 0 4}$ & 53 \\
\hline $\mathbf{2 0 0 4 - 2 0 0 5}$ & 50 \\
\hline $\mathbf{2 0 0 5 - 2 0 0 6}$ & 45 \\
\hline $\mathbf{2 0 0 6 - 2 0 0 7}$ & 45 \\
\hline $\mathbf{2 0 0 7 - 2 0 0 8}$ & 47 \\
\hline $\mathbf{2 0 0 8 - 2 0 0 9}$ & 54 \\
\hline
\end{tabular}

La Universidad de León para valorar el progreso y los resultados de aprendizaje de los títulos utiliza los siguientes datos como referencia:

- Tasa de graduación: Porcentaje de estudiantes que finalizan la titulación en los años establecidos en el plan o en uno más.

- Tasa de abandono: Indica el porcentaje de estudiantes que no se matricularon en los dos últimos cursos.

- Tasa de eficiencia: Relación entre el número de créditos superados por los estudiantes y el número de créditos que se tuvieron que matricular en ese curso y en anteriores, para superarlos. La tasa de eficiencia de una titulación se mide de dos formas: sobre el conjunto de créditos superados a lo largo de la carrera por los alumnos titulados en un determinado ańo académico o bien sobre los créditos superados en las materias de una titulación en un determinado ańo académico.

- Tasa de éxito: Relación porcentual entre el número total de créditos superados por los alumnos y el número total de créditos presentados a examen.

- Tasa de rendimiento: Relación entre créditos superados y créditos matriculados.

En relación con la tasa de graduación cabe señalar que el programa formativo de Biblioteconomía y Documentación tiene una duración de tres cursos académicos, con lo que el tiempo previsto para la finalización de los estudios por parte del alumnado es en principio de tres años. Como podemos observar el porcentaje de la tasa de graduación ha disminuido en los últimos cursos.

Tabla 3 - Tasas de Graduación y de Abandono

\begin{tabular}{|l|c|c|c|}
\hline & Inician & Graduados & Abandonan \\
\hline $\mathbf{2 0 0 3 - 2 0 0 4}$ & & $41(43 \%)$ & $33 \%$ \\
\hline $\mathbf{2 0 0 4 - 2 0 0 5}$ & 19 & $23(65 \%)$ & $10 \%$ \\
\hline $\mathbf{2 0 0 5 - 2 0 0 6}$ & 13 & $20(52 \%)$ & $24 \%$ \\
\hline $\mathbf{2 0 0 6 - 2 0 0 7}$ & 25 & $8(32 \%)$ & $37 \%$ \\
\hline $\mathbf{2 0 0 7 - 2 0 0 8}$ & 30 & $9(30 \%)$ & $23 \%$ \\
\hline
\end{tabular}


En la Diplomatura de Biblioteconomía y Documentación la tasa de abandono que corresponde a 2007-2008 y 2008-2009, en que están presentes los alumnos semipresenciales, no permite apreciar diferencias significativas con respecto a los anteriores, si bien los estudios acerca del e-learning ponen de relieve la especial motivación que requiere el seguimiento en solitario de la enseńanza, máxime cuando se compatibiliza con ocupaciones laborales, por esta razón, el porcentaje de abandono, en estas enseńanzas suele ser elevado (Allan, 2004).

En el estudio realizado en 2008 (Rodríguez Bravo y Morán Suárez) se constataba un significativo porcentaje de abandono (32\%) durante el primer curso entre los alumnos semipresenciales. Dicho abandono se producía durante el primer trimestre, alegando los estudiantes que se retiraban que les suponía demasiado esfuerzo el seguimiento del curso. El abandono no guardaba relación con el éxito obtenido en los exámenes ya que ninguno de los estudiantes que dejaron los estudios llegó a acudir a la convocatoria de las asignaturas de primer cuatrimestre en febrero.

En el futuro no se podrán medir las tasas de graduación y de abandono con los criterios actuales, dado que los futuros alumnos se matricularán sólo en opción semipresencial. La duración de sus estudios no tendrá una pauta estándar. Cada alumno podrá diseñar su aprendizaje y su itinerario curricular en función de sus necesidades y de su disponibilidad horaria.

En cuanto a la tasa de eficiencia a lo largo de los últimos años la oscilación es muy leve. Hallándose entre un $74 \%$ y un $80 \%$. Esta situación refleja que el cambio de modalidad de enseñanza no ha supuesto ninguna variación significativa en los primeros ańos de implantación del nuevo sistema.

Por lo que se refiere a las tasas de éxito y de rendimiento, los datos de que disponemos son los siguientes:

Tabla 4 - Tasa de éxito y Tasa de rendimiento

\begin{tabular}{|l|c|c|}
\hline Cursos & Tasa de Éxito & Tasa de Rendimiento \\
\hline $\mathbf{2 0 0 2 - 2 0 0 3}$ & $84 \%$ & $65 \%$ \\
\hline $\mathbf{2 0 0 3 - 2 0 0 4}$ & $88 \%$ & $70 \%$ \\
\hline $\mathbf{2 0 0 4 - 2 0 0 5}$ & $85 \%$ & $59 \%$ \\
\hline $\mathbf{2 0 0 5 - 2 0 0 6}$ & $90 \%$ & $63 \%$ \\
\hline $\mathbf{2 0 0 6 - 2 0 0 7}$ & $96 \%$ & $68 \%$ \\
\hline $\mathbf{2 0 0 7 - 2 0 0 8}$ & $94 \%$ & $64 \%$ \\
\hline
\end{tabular}

La tasa de éxito es elevada, se sitúa entre el $84 \%$ y el $96 \%$. Por su parte, la tasa de rendimiento es inferior, posiblemente debido a la obligación de matricularse el alumno de primer curso de todos los créditos y a la situación laboral de un buen número de nuestros alumnos ya referida. En cualquier caso, más del $50 \%$ de los alumnos superan la totalidad de las asignaturas en el tiempo previsto para una promoción.

\section{Objetivos y metodología}

El objetivo de este trabajo es el análisis de los medios utilizados para la transmisión de contenidos y dotación de competencias en las asignaturas de Análisis Documental 
(catalogación), Análisis del Contenido Documental y Lenguajes Documentales. Dichas asignaturas se imparten en $1^{\circ}, 2^{\circ}$ y $3^{\circ}$ curso respectivamente. Análisis Documental y Lenguajes Documentales son asignaturas troncales, anuales y de 10 créditos, mientras que Análisis del Contenido Documental es una asignatura obligatoria de universidad, de 6 créditos y que se ha venido impartiendo en el segundo cuatrimestre del curso. Las tres asignaturas tienen el mismo profesor responsable, que imparte toda o parte de la materia y se utiliza la misma metodología en las tres. Por último cabe señalar que se trata de asignaturas muy prácticas, en todos los casos el $60 \%$ de la carga docente es práctica.

Si bien es cierto que intuíamos algunas de las respuestas obtenidas, deseábamos confirmarlas con las evidencias que nos podían aportar las opiniones de los alumnos y los datos numéricos de que se dispone: alumnos matriculados en las asignaturas, alumnos presentados a las convocatorias de 2009 y alumnos aprobados. Estos datos se ponen en relación con los valores generales que nos ha proporcionado la Oficina de Calidad de los últimos cursos para el conjunto de la titulación de Biblioteconomía y Documentación. Asimismo, se comparan los resultados obtenidos por estos alumnos y por aquellos que cursan los estudios en modo presencial.

Con el fin de recabar las opiniones de los estudiantes se distribuyó una encuesta a los alumnos semipresenciales de los tres cursos de la diplomatura en la que se les pedía la valoración de los mecanismos utilizados para la enseñanza-aprendizaje de las mencionadas asignaturas. Se cuestionó a aquellos alumnos que se presentaron al examen ordinario de junio de 2009 por entender que eran los que habían realizado seguimiento de las asignaturas y podían proporcionar respuesta a los ítems planteados. Se entregaron las encuestas a la vez que el examen, comunicando a los estudiantes que era voluntaria su respuesta y, por supuesto, anónima.

A los alumnos de segundo curso se les permitía también dar su opinión sobre la asignatura cursada en primero y a los estudiantes de tercer curso sobre las asignaturas de primero y segundo. No obstante, sólo se tuvieron en cuenta las opiniones vertidas sobre asignaturas cursadas en años anteriores en un caso, a saber, las opiniones de los alumnos de tercero sobre la materia de Análisis del Contenido Documental. Los motivos fueron los siguientes, de un lado que contábamos con un número escaso de respuestas en consonancia con los estudiantes matriculados en esta asignatura que son poco numerosos debido a que la asignatura de primer curso, Análisis Documental, actúa como llave para la materia de segundo curso, y de otro la certeza de que el modelo de enseñanza y los mecanismos de dotación de competencias al alumno, había sido idéntico en el curso 2007-2008, dado que la asignatura Análisis del Contenido Documental había sido impartida íntegramente por quien escribe estas líneas en ambos cursos.

En concreto, se solicitaba la valoración numérica en una escala del 1 al 5 de las siguientes actividades y/o materiales elaborados que habían sido proporcionados a los estudiantes por mediación de la plataforma aula@unileon, siendo el 5 el valor que indica el mayor grado de satisfacción y 1 el valor que refleja un menor acuerdo con el sistema empleado:

- Temas elaborados

- Cuestionarios de autoevaluación

- Explicaciones de las prácticas a realizar

- Ejercicios prácticos planteados 
- Sesiones presenciales

- Tutorías virtuales

La salvedad a señalar se refiere a la asignatura Lenguajes Documentales, en ella no se preguntaba acerca de los cuestionarios de evaluación porque no se utilizaron. En la asignatura de primero, Análisis Documental, se plantean cuestionarios de evaluación tema a tema para facilitar al alumno el discernimiento de los contenidos esenciales de cada tema. En la asignatura de segundo curso, Análisis del Contenido Documental, dichos cuestionarios se plantean por bloques, en total se trata de tres cuestionarios, entendiendo que se trabaja con alumnos más expertos que no requieren un seguimiento tan pormenorizado para conseguir los objetivos mínimos planteados. Utilizando ese mismo criterio, los cuestionarios se suprimen en la materia que impartimos en tercer curso.

De igual modo, se les pedía en respuesta abierta su opinión sobre:

- Puntos fuertes en la impartición de la materia

- Puntos débiles en la impartición de la materia

- Sugerencias de mejora

\section{Resultados}

\subsection{Análisis documental}

En esta asignatura, troncal y de primer curso, durante 2008-2009 hubo 42 alumnos matriculados. 11 de ellos de modo presencial y 31 de modo semipresencial. Del total de 42 alumnos, 36 eran de nuevo ingreso, los 6 restantes eran estudiantes que ya habían estado matriculados en la asignatura y que, o bien la habían suspendido, o bien no se habían presentado a las convocatorias de exámenes correspondientes.

El número de estudiantes presentados a la convocatoria de junio fue de 24, 9 presenciales y 15 no presenciales. Se observa que el porcentaje de alumnos semipresenciales que acudieron al examen final en la primera convocatoria es inferior al porcentaje de alumnos presenciales. La tasa de rendimiento de la asignatura se sitúa en un $57 \%$, por tanto, cercana a la media de la titulación de los últimos cursos que se encuentra por encima del 60\%, media que sin duda se alcanzará en la convocatoria de septiembre. Como hemos comentado, durante el primer curso se produce un abandono significativo entre los estudiantes semipresenciales.

Por lo que se refiere al éxito obtenido en la convocatoria, 21 de los 24 estudiantes superaron las pruebas planteadas con éxito, los alumnos presenciales aprobaron todos, los 9, y de los no presenciales 12 de 15. El grado de consecución de los objetivos mínimos es elevado, si bien superior en el caso de los alumnos presenciales. La tasa de éxito, un $87 \%$, se halla dentro de los parámetros generales de la titulación que oscilan entre un $84 \%$ y un $96 \%$ y ascenderá, igualmente, en la convocatoria de septiembre.

En relación a los datos obtenidos de las encuestas cabe señalar que se entregaron 15 encuestas a los alumnos que concurrieron a la convocatoria de junio y se recibieron 13 contestaciones. Los resultados obtenidos fueron los siguientes:

Los alumnos valoraron muy positivamente los medios empleados en el proceso de enseñanza-aprendizaje de la asignatura. Así otorgaron una puntuación de 4 o 5 a cinco 
de los seis ítems sobre los que se les preguntaba: Temas elaborados, Cuestionarios de evaluación, Explicaciones de las prácticas a realizar, Ejercicios prácticos planteados y Tutorías virtuales.

Ligeramente menos satisfechos se mostraron respecto a las Sesiones presenciales. Siete alumnos puntuaron las clases presenciales con un 4 o 5 , tres alumnos con un 3 , y los demás no contestaron. La ausencia de respuesta obedece a la circunstancia de que algunos alumnos semipresenciales no acuden a las sesiones presenciales por vivir en provincias alejadas de León o por no permitírselo su situación laboral.

En relación con los puntos fuertes señalados, los estudiantes valoran positivamente los contenidos de los temas, los cuestionarios de autoevaluación y las prácticas planteadas. También la accesibilidad y amabilidad del profesorado. Cabe señalar que todos los estudiantes señalan fortalezas.

Por lo que se refiere a los puntos débiles, los alumnos ponen de manifiesto la dificultad de aprender catalogación de forma semiautónoma. Algunos alumnos piden más prácticas y mayor comunicación individualizada con el profesor o más sesiones presenciales. Tres estudiantes no señalan debilidades.

Las sugerencias de mejora inciden en los mismos aspectos señalados en los puntos débiles: la conveniencia de incidir más en las prácticas, de disponer de mayor número de sesiones presenciales y de que se propicie más la comunicación individualizada entre el profesor o profesores y el alumno. Seis estudiantes no plantean sugerencia alguna.

\subsection{Análisis del contenido documental}

En esta asignatura, obligatoria y de segundo cuatrimestre de segundo curso, durante 2008-2009 hubo 23 alumnos matriculados. Si bien en el curso 2007-2008 ingresaron 30 alumnos nuevos en primero sólo 23 se matricularon en esta asignatura. Como se ha señalado, la asignatura de Análisis Documental hace de llave y quien la tiene suspensa no puede acceder a cursar Análisis del Contenido Documental. Otro factor a considerar es que algunos alumnos semipresenciales optan por no matricularse de los cursos completos en segundo y en tercero dado que prefieren cursar la titulación más despacio.

De los 23 alumnos matriculados, 8 alumnos eran presenciales y 15 no presenciales. El porcentaje de estudiantes presentados fue de 13. De ellos 4 fueron alumnos presenciales y 9 no presenciales. Se observa en esta asignatura un mayor rendimiento en el caso de los alumnos semipresenciales. Cabe señalar, no obstante, que sólo tres alumnos presenciales de los ocho matriculados lo fueron efectivamente, es decir acudieron a clase. Los demás son alumnos que iniciaron sus estudios en cursos anteriores y que avanzan lentamente en sus estudios por compatibilizar estudios y trabajo, normalmente. La tasa de rendimiento, en este caso es de un 56,5\%. Muy similar a la obtenida en la asignatura de primer curso y próxima, asimismo, a la media de la titulación.

Por lo que se refiere al nivel de consecución de los objetivos, en este caso, es elevado. De los 13 estudiantes sólo no supera la convocatoria una alumna presencial. Por tanto, la tasa de éxito se halla por encima del 92\%. Confiamos en alcanzar el $100 \%$ en la convocatoria de septiembre. 
En relación a los datos obtenidos de las encuestas, cabe señalar que se entregaron 9 encuestas el día del examen de la asignatura Análisis del Contenido Documental. Como se ha señalado anteriormente, al parecernos muy reducido el número de contestaciones, tuvimos en consideración las opiniones que nos proporcionaron los alumnos de tercero que tuvieron a bien cubrir el apartado referente a la asignatura cursada un ańo antes. En total el estudio se hace sobre 17 encuestas.

Lo primero que es preciso señalar es que las opiniones sobre esta asignatura son más heterogéneas y la calificación de los ítems oscila entre el 3 y el 5, si bien en dos de los ítems hay una persona que otorga una puntuación de 2 y en esos mismos ítems dos personas no responden.

Los cuestionarios de evaluación y los ejercicios prácticos planteados son los aspectos mejor valorados, en el primer caso catorce personas los valoran con un 4 o un 5, siendo quince en el segundo. En ambos casos son dos las personas que otorgan un 3 y con respecto a los cuestionarios de evaluación de los temas otra persona no se manifiesta.

Los temas elaborados y las explicaciones sobre las prácticas a realizar obtienen una valoración algo inferior. En ambos casos trece estudiantes otorgan valores de 4 o 5 puntos, y cuatro alumnos los califican con un 3. En el primer caso es mayor el número de estudiantes que se inclinan por la puntuación del 5 que en el segundo.

Las valoraciones menos positivas son las otorgadas a los ítems referentes a las sesiones presenciales y a las tutorías virtuales, siendo estas últimas las inferiormente consideradas. Por lo que se refiere a las sesiones presenciales, doce estudiantes las valoran con un 4 o un 5, dos alumnos con un tres, un estudiante con un 2 y hay dos alumnos que no responden. En cuanto a las tutorías virtuales, son también dos los alumnos que no se manifiestan, un estudiante que puntúa la actividad con un 2 , cinco personas que califican con un 3 y nueve que realizan una valoración de 4 o 5 . Se muestra, por tanto esta última actividad como la que recibe menor consideración.

Con respecto a los puntos fuertes señalados, se valora positivamente el peso concedido a las prácticas. En este aspecto inciden nueve alumnos. Asimismo, se hace referencia a la importancia y utilidad de la materia, a los contenidos de los temas, que se califican de claros y a la buena disposición del profesorado para resolver dudas. Son cuatro los estudiantes que no responden.

En relación con los puntos débiles algunos alumnos consideran que la asignatura tiene pocos créditos y que se necesitaría más tiempo para poder realizar más prácticas. Otros alumnos plantean la necesidad de una mayor corrección individualizada de las prácticas y de un mayor número de sesiones presenciales. Ocho alumnos no señalan debilidades.

Por lo que se refiere a las sugerencias de mejora, en consonancia con los puntos débiles señalados, se propone que la asignatura se convierta en anual para que exista la posibilidad de realizar más prácticas, que se convoquen más clases presenciales y que se realice un seguimiento más personalizado del alumno.

Por lo que se refiere al deseo de algunos alumnos de que sus prácticas se comenten individualizadamente en las tutorías virtuales, conviene aclarar lo siguiente. En las tres asignaturas, cuyo método de impartición estamos analizando, se realizan correcciones individualizadas de las prácticas pero, salvo excepciones, no se ofrece retroinformación personalizada a los estudiantes. Se presenta una corrección estándar y se comentan los errores más comunes. Los alumnos tienen que autocorregirse. Excepciones las 
constituyen las prácticas de elaboración de resúmenes de esta asignatura y el ejercicio de construcción de un microtesauro que se propone en la asignatura de Lenguajes Documentales, en ambos casos se comentan los ejercicios con los estudiantes uno por uno.

\subsection{Lenguajes documentales}

En esta asignatura, troncal y de tercer curso, durante 2008-2009 hubo 26 alumnos matriculados. De ellos 7 han sido alumnos presenciales y 19 no presenciales. Al examen final de junio acudieron 22 de los 26 estudiantes. El total de los estudiantes presenciales y 15 de los estudiantes semipresenciales. En total la tasa de rendimiento asciende a un $84 \%$ constituyéndose en la más elevada de las tres asignaturas y por encima de los parámetros generales de la titulación.

Por lo que se refiere al éxito obtenido es de más del 95\%. Superan la convocatoria 21 de los 22 alumnos. Suspende una alumna semipresencial, antigua alumna presencial que ha retomado ahora los estudios aprovechando las facilidades que los estudios semipresenciales ofrecen a los alumnos insertos en el mercado laboral. Esperamos que en septiembre podamos conseguir un $100 \%$ de éxito también en esta asignatura.

En relación a las encuestas, se recabaron 14 respuestas. La valoración que obtienen los distintos ítems ofrece una oscilación limitada entre el 5 y el 3. Como en las otras asignaturas, hay estudiantes que no responden a los apartados de sesiones presenciales y de tutorías virtuales, entendemos que porque no hacen uso de ellas. Se trata de dos estudiantes en cada caso.

De los catorce alumnos que contestaron a la encuesta once consideran positivamente, otorgando puntuaciones de 4 o 5, la mayoría de los ítems, a saber: los temas elaborados, las explicaciones de las prácticas a realizar, los ejercicios prácticos planteados y las sesiones presenciales. De entre estos ítems son los ejercicios prácticos los más aplaudidos dado que son nueve los estudiantes que los valoran con un 5. Son tres los estudiantes que puntúan con un 3 o no contestan.

Con las tutorías virtuales los estudiantes se muestran ligeramente menos satisfechos, ocho las valoran con puntuaciones altas, cuatro con puntuación intermedia, un 3, y, como se ha mencionado, dos alumnos no se manifiestan.

En relación a las fortalezas de la asignatura, se valoran positivamente los contenidos y la claridad de los temas y sobre todo las prácticas planteadas. Se resalta la utilidad de las prácticas y se considera que el peso que se les concede en la asignatura es adecuado. Se destaca la importancia de las tutorías virtuales como medio de comunicación y la atención, accesibilidad y amabilidad del profesorado. Cinco alumnos no contestan.

Como debilidades se pone de relieve la dificultad que para el aprendizaje de una asignatura tan práctica supone la ausencia de contacto diario con el profesor. Tres estudiantes piden que se den más prácticas o que la asignatura tenga más créditos. Cuatro plantean la necesidad de obtener más correcciones individualizadas de sus prácticas. Un alumnos solicita más sesiones presenciales otro se queja de que la plataforma no es un buen medio de comunicación. Por último cinco alumnos no señalan puntos débiles. 
Las sugerencias de mejora inciden en los mismos aspectos señalados en los puntos débiles dado que suelen ser los mismos estudiantes los que cubren ambos apartados: tres alumnos sugieren que se convoquen más sesiones presenciales, otros tres que se den más clases prácticas o que la asignatura tenga mayor duración, por último, una persona pide correcciones individualizadas. Son diez los alumnos que no realizan sugerencias.

\section{Conclusiones}

Cabe señalar el alto grado de satisfacción del alumnado con las asignaturas obligatorias del área de Representación de la Información y/o Organización del Conocimiento que refuerza las conclusiones del trabajo de análisis de los primeros pasos de la experiencia semipresencial en la Universidad de León (Rodríguez Bravo y Morán Suárez, 2008).

Los resultados obtenidos durante el presente curso de alumnos presentados y aprobados en la convocatoria de junio de 2009 son satisfactorios. Los mejores resultados los presenta la asignatura de Lenguajes Documentales que se imparte en tercer curso. Las razones que podemos señalar son diversas. De un lado, que se trata de una promoción muy motivada, tanto en el caso del grupo de alumnos presenciales como en el caso de los alumnos semipresenciales. De otro, que son alumnos de tercer año más expertos en su aprendizaje y que conocen ya los mecanismos de la asignatura por haber trabajado con ellos en los cursos anteriores. Finalmente, los contenidos son continuación de los vistos en segundo curso, lo que puede resultar ventajoso, si bien las prácticas a desarrollar no están exentas de dificultades, como es el caso de la construcción del microtesauro comentado, o la utilización de las clasificaciones y las listas de encabezamientos de materia.

Los resultados de las asignaturas de primero y segundo cursos son bastante similares en lo que se refiere a rendimiento y ligeramente inferior la tasa de éxito en el caso de la materia de Análisis Documental. Nuestra experiencia en la impartición de estas asignaturas desde el curso 1995-1996, en que se inició el presente plan de estudios, es que la catalogación, contenido que se enseña en la asignatura de Análisis Documental de primero, resulta atractiva al alumnado pero su inagotable casuística le supone una mayor dificultad que la indización o el resumen de documentos, contenidos esenciales de la materia de Análisis del Contenido Documental. Los escollos que la catalogación presenta, per se, se acrecientan para el grupo de alumnos semipresenciales, que no tienen acceso diario a las explicaciones del profesor.

Como se ha señalado se trata de tres asignaturas muy prácticas, en todos los casos los créditos prácticos superan a los teóricos. Esta circunstancia hace que su impartición a distancia presente un alto grado de dificultad, que ya se ponía de relieve en el estudio llevado a cabo en 2008 sobre la experiencia de la impartición de la titulación en modo semipresencial del primer año (Rodríguez Bravo y Morán Suárez, 2008: 383). Nos congratulamos, por tanto, de los resultados obtenidos por los alumnos semipresenciales que no desmerecen a los de los estudiantes presenciales, salvando el caso de la catalogación señalado. La motivación y el interés de estos alumnos son los principales responsables de su éxito. 
Curiosamente, son los alumnos de primer curso los que se muestran más satisfechos con la metodología empleada, si bien el grado de satisfacción general es alto, únicamente un alumno de segundo curso valora con una puntuación de 2 dos ítems. Predominan las puntuaciones de 5 y 4 en la mayoría de los ítems por los que se pregunta, y salvo el caso señalado la valoración no desciende del 3 .

Se puede por tanto hablar de unanimidad en la aceptación que las asignaturas, en sí mismas y sus mecanismos de impartición, han tenido entre el alumnado. Los estudiantes consideran fundamentales los contenidos de las tres materias y tienen en una apreciación elevada las prácticas que en ellas se realizan. Incluso, plantean que se amplíe la duración de la asignatura de segundo curso que es cuatrimestral. En consonancia con esta circunstancia otorgan las máximas puntuaciones a cuatro de las actividades y/o materiales elaborados para facilitar el aprendizaje al alumnado, a saber, los temas elaborados, los cuestionarios de autoevaluación sobre dichos temas, loe ejercicios prácticos planteados y las explicaciones que se ofrecen para realizar dichas prácticas. No obstante, los alumnos de tercer curso no parecen haber echado en falta los cuestionarios de autoevaluación por temas.

Algo menor es la consideración acerca de las tutorías virtuales y de las sesiones presenciales. Respecto a ambos mecanismos cabe señalar que ya en el estudio anterior (Rodríguez Bravo y Morán Suárez, 2008: 381-383 y 387) se ponía de relieve la dudosa satisfacción del alumnado. Los estudiantes, como hemos constatado, desean una atención más personalizada y contestaciones individualizadas a sus dudas y cuestiones a resolver. Por esta razón, los alumnos que pueden acudir a las sesiones presenciales desean que se incrementen. No obstante, los alumnos a los que no les es posible acudir no son partidarios de dicho aumento porque les hace sentirse en desventaja. Es preciso señalar que las sesiones presenciales han sido, ciertamente, escasas. Se ha venido convocando una sesión cada mes y medio o dos meses y el tiempo disponible por asignatura en dichas sesiones era de una hora.

Por otra parte, los intentos que hemos realizado de utilización del foro como medio de comunicación del alumnado no han tenido éxito. Los alumnos no han demostrado aprecio por las tutorías virtuales colectivas y demandan atención individualizada por medio del correo electrónico. Creemos que la ausencia de corrección personalizada de algunas prácticas son las responsables de la menor valoración que recibe el ítem de tutorías virtuales.

Sin duda, son estos los puntos débiles a resolver en la impartición del nuevo Grado en Información y Documentación. Dado que la Universidad de León ya sólo atenderá a alumnos semipresenciales, no teniendo que duplicar los profesores tiempo y esfuerzo entre la docencia en el aula y a distancia, sin duda se podrá atender a los estudiantes, como requieren, tanto en sesiones presenciales que prevemos aumentar a dos horas/asignatura semanalmente, como por medio de las tutorías virtuales personalizadas. Así mismo, esperamos conseguir potenciar la actividad de los foros, medio imprescindible de comunicación en la enseñanza a distancia (Allan, 2004). 


\section{Referências bibliográficas}

Allan, B. (2004). E-learning and teaching in library and information services. London: Facet Publishing, 2002 (2004 repr.). ISBN 1-856004-439-4

Rodríguez Bravo, B.; Morán Suárez, Ma A. (2008). La enseñanza semipresencial de la Diplomatura de Biblioteconomía y Documentación: primeros pasos de una nueva experiencia en la Universidad de León. En: José Antonio Frías y Críspulo Travieso (eds.). Formación, investigación y mercado laboral en información y documentación en España y Portugal. Salamanca: Ediciones Universidad de Salamanca. P. 377-388.

\section{Agradecimientos}

Deseo dejar constancia de mi agradecimiento a los alumnos que han contestado la encuesta $y$, en general, a los estudiantes de las tres últimas promociones que han tenido que sufrir las consecuencias de la falta de experiencia de sus profesores con la enseñanza a distancia.

Igualmente, agradezco a la Oficina de Calidad de la Universidad de León los datos que me ha facilitado y que me han servido para contextualizar este estudio. 